\title{
IgE Reactivity of Recombinant Pac c 3 from the Asian Needle Ant (Pachycondyla chinensis)
}

\author{
Kyoung Yong Jeong ${ }^{\mathrm{a}}$ Myung-hee $\mathrm{Yi}^{\mathrm{b}}$ Mina Son $^{\mathrm{a}}$ Dongpyo Lyu ${ }^{\mathrm{c}}$ \\ Jae-Hyun Lee $^{\mathrm{a}}$ Tai-Soon Yong ${ }^{\mathrm{b}}$ Jung-Won Park ${ }^{\mathrm{a}}$ \\ a Department of Internal Medicine, Institute of Allergy, and b Department of Environmental Medical Biology, \\ Institute of Tropical Medicine, Arthropods of Medical Importance Resource Bank, Yonsei University College of \\ Medicine, Seoul, and 'Department of Forest Sciences, Sangji University, Wonju, Korea
}

\section{Key Words}

Ant sting anaphylaxis · Antigen $5 \cdot$ Pac c $3 \cdot$ Pachycondyla chinensis

\begin{abstract}
Background: Stings from the Asian needle ant are an important cause of anaphylaxis in East Asia. A 23-kDa protein homologous to antigen 5 is the major allergen produced by these ants. In this study, we aimed to produce a recombinant antigen 5 allergen, Pac c 3. Methods: Recombinant Pac c 3 allergen from the Asian needle ant was expressed in Pichia pastoris and purified by ammonium sulfate precipitation and $\mathrm{Ni}$ affinity chromatography. IgE reactivity was demonstrated by ELISA and immunoblotting. Results: The recombinant protein was recognized in 5 of $6(83.3 \%)$ serum samples from patients with demonstrated anaphylaxis to ants. IgE reactivity to an antigen 5 allergen from Asian needle ant venom sac extract was specifically inhibited by the recombinant protein. It was also able to inhibit IgE binding to the vespid allergen Ves v 5 by ImmunoCAP analysis, indicating the presence of cross-reactivity. Conclusion: A recombinant Pac c 3, cross-reactive with Ves $\vee 5$, from the Asian needle ant was
\end{abstract}

successfully produced in the methylotrophic yeast $P$. pastoris. This protein could be useful for the development of component-resolved diagnostics.

(c) 2016 S. Karger AG, Base

\section{Introduction}

Some species of ants belonging to the Myrmicinae and Ponerinae subfamilies possess a stinging apparatus. In Korea, Pachycondyla chinensis, Euponera chosensis, and Crematogaster matsumurai have been reported to sting humans [1-3]. The Asian needle ant, $P$. chinensis, is the most common reported stinging ant [4], and anaphylaxis is one of the most common symptoms of subjects who are stung by $P$. chinensis $[5,6]$. In $P$. chinensis-infested areas, approximately $23 \%$ of people are reported to be sensitized to this insect, and $2.1 \%$ of these have experienced systemic anaphylactic reactions [7]. A $23-\mathrm{kDa}$ allergen that shows $50 \%$ sequence homology with antigen 5 from

The initial data of this paper was presented as an abstract at the World Allergy Congress 2015, October 14-17, Seoul, Korea.

\section{KARGER}

E-Mail karger@karger.com www.karger.com/iaa
(C) 2016 S. Karger AG, Basel

$1018-2438 / 16 / 1692-0093 \$ 39.50 / 0$
Correspondence to: Dr. Jung-Won Park

Department of Internal Medicine, Institute of Allergy

Yonsei University College of Medicine, 50-1 Yonsei-ro, Seodaemun-gu

Seoul 03722 (Korea)

E-Mail parkjw@yuhs.ac 
Table 1. Clinical features of the study patients

\begin{tabular}{lllllll}
\hline $\begin{array}{l}\text { Patient } \\
\text { No. }\end{array}$ & Sex & $\begin{array}{l}\text { Age, } \\
\text { years }\end{array}$ & $\begin{array}{l}\text { Causes of } \\
\text { anaphylaxis }\end{array}$ & $\begin{array}{l}\text { SPT (wheal } \\
\text { size), cm }\end{array}$ & $\begin{array}{l}\text { IgE to rPac c 3, } \\
\mathrm{kU} / \mathrm{A}\end{array}$ & $\begin{array}{l}\text { IgE to rVes v 5, } \\
\mathrm{kU} \mathrm{U}_{\mathrm{A}} / \mathrm{l}\end{array}$ \\
\hline 1 & $\mathrm{~F}$ & 51 & Ant sting & $\mathrm{ND}$ & 35.60 & 7.20 \\
2 & $\mathrm{~F}$ & 47 & Bee and ant sting & 5 & 17.10 & 4.95 \\
3 & $\mathrm{M}$ & 38 & Ant sting & 3 & 1.30 & 0.28 \\
4 & $\mathrm{~F}$ & 33 & Ant sting & 3 & 0.05 & 0.05 \\
5 & $\mathrm{M}$ & 22 & Bee and ant sting & 5.5 & 4.21 & 1.81 \\
6 & $\mathrm{~F}$ & 34 & Ant sting & 4 & 4.12 & 1.80 \\
\hline
\end{tabular}

$\mathrm{ND}=$ Not determined; SPT $=$ skin prick test.

wasps was identified by proteomic analysis of a sample from the $P$. chinensis abdomen, which contains the venom sac [8]. This protein was recognized in the serum IgE from 6 of $7(85.7 \%)$ patients with anaphylactic reactions to the Asian needle ant. It was designated as Pac c 3 according to the guidelines of the Allergen Nomenclature Subcommittee of the International Union of Immunological Societies.

Antigen 5 constitutes approximately $10-30 \%$ of the vespid venom proteins [9]. The physicochemical properties of antigen 5 are known to be similar to those of a neurotoxin isolated from the venom of an Asian hornet, Vespa mandarinia [10], and antigen 5 also shares some structural homology with pathogenesis-related proteins that are produced in response to various stress factors [11]. Antigen 5 proteins are also detected in the saliva of bloodfeeding ticks, flies and mosquitoes, suggesting a function either in suppression of the host immune system or in the prevention of blood clotting [12]. However, the function of antigen 5 in vespid venom is not known.

The superior diagnostic and therapeutic value of venom has been demonstrated for patients with insect venom allergies $[13,14]$. Moreover, the value of component-resolved diagnosis using purified allergens for Hymenoptera allergy has been described [15-18]. Production of recombinant Pac c 3 from the Asian needle ant could be particularly useful as the total extract is available only in limited amounts. Expression of recombinant antigen 5 protein in prokaryotic systems has not been successful, and recombinant antigen 5 should be produced in eukaryotic systems such as insect cell lines or yeasts.

In the present study, we produced a recombinant Pac c 3 in a Pichia system and evaluated its allergenicity with the sera of patients with $P$. chinensis anaphylaxis.

\section{Materials and Methods}

Expression and Purification of Recombinant Allergen

The open reading frame of the Pac c 3 (GenBank accession No. EU516327) was obtained by PCR amplification using cDNA cloned into the $\mathrm{pCR}{ }^{\circledR} \mathrm{II}-\mathrm{TOPO}$ vector (Invitrogen, Carlsbad, Calif., USA) as a template with the following oligonucleotide primers: forward primer $5^{\prime}$-CTCGAGAAAAGAGAGGCTGAAGCTACTGATTACGAAGATTTAAAAACTGAAGGCGGCGCGGTG-3' and reverse primer $5^{\prime}$-GCGGCCGCTTAATGATGATGATGATGATGTTGGTATATTGGTGCGCC- $3^{\prime}$. The AAAAGAGAGGCTGAAGCT (underlined) sequence was introduced into the forward primer for signal cleavage, and the ACTGATTACGAAGATTTAAAA (underlined and italicized) sequence was incorporated based on the $\mathrm{N}$-terminal amino acid sequence of the native allergen by Edman degradation. A sequence corresponding to six histidine residues (underlined) was incorporated into the reverse primer to facilitate purification of the recombinant protein. XhoI and NotI restriction sites (italicized) were also added to the primer sequences for cloning into the pPIC9 yeast expression vector (Invitrogen). The PCR-amplified DNA fragments were ligated with pCR4 TOPO vector (Invitrogen) and then digested with XhoI and Not $\mathrm{I}$ restriction enzymes. The digested DNA fragment was subcloned into the pPIC9 vector. StuI-linearized plasmid was transformed into yeast GS115 cells using a PichiaEasyComp Kit (Invitrogen). His+ transformants that grow on histidine-deficient medium were selected on RDB plates ( $1 \mathrm{M}$ sorbitol, $1 \%$ dextrose, $4 \times$ $10^{-5} \%$ biotin, $1.34 \%$ yeast nitrogen base without amino acids and $0.005 \%$ each of L-glutamic acid, L-isoleucine, L-leucine, L-lysine and L-methionine). Integration of cDNA into the yeast genome was confirmed by PCR using genomic DNA isolated from individual colonies as templates with $5^{\prime} \mathrm{AOX}$ and $3^{\prime} \mathrm{AOX}$ primers. A clone with correct integration was grown for $24 \mathrm{~h}$ at $30^{\circ} \mathrm{C}$. Culture supernatant was concentrated by ammonium sulfate precipitation (70\%). The precipitates were dissolved and dialyzed against binding buffer (10 mM imidazole, $300 \mathrm{mM} \mathrm{NaCl}$ and $50 \mathrm{~mm}$ sodium phosphate, $\mathrm{pH}$ 8.0). Recombinant protein was purified using $\mathrm{Ni}$ nitrilotriacetic acid resin (Qiagen, Valencia, Calif., USA) and elution buffer ( $250 \mathrm{~mm}$ imidazole, $300 \mathrm{~mm} \mathrm{NaCl}$ and $50 \mathrm{~mm}$ sodium phosphate, $\mathrm{pH}$ 8.0). Protein concentration was determined using the Bradford assay (Bio-Rad, Hercules, Calif., USA), and purified protein was analyzed by electrophoresis through a $12 \%$ polyacryl-
Jeong/Yi/Son/Lyu/Lee/Yong/Park 
amide gel containing sodium dodecyl sulfate (SDS) under reducing conditions. The protein band was cut after staining with Coomassie brilliant blue R250 and subjected to LC-coupled ESI-MS/ MS analysis for the confirmation of protein identity at ProteomeTech (Seoul, Korea).

\section{Serum Samples}

Six of the 7 serum samples from patients with ant anaphylaxis that were used for the original identification of Asian needle ant allergens [8] were used in this study (table 1). Sera from 8 subjects who were sensitive to house dust mites and from 16 healthy controls were also included. This study was approved by the institutional review board of our institute (4-2013-0397).

\section{Specific IgE Reactivity to Recombinant Protein}

A microtiter plate was coated with $100 \mu \mathrm{l}$ of recombinant protein $(2 \mu \mathrm{g} / \mathrm{ml}$ in $50 \mathrm{~mm}$ sodium carbonate, $\mathrm{pH}$ 9.6). After washing with phosphate buffered saline containing $0.05 \%$ Tween 20 (PBST), the plate was blocked with 3\% skim milk in PBST and then incubated for $1 \mathrm{~h}$ with $50 \mu \mathrm{l} /$ well of sera diluted 1:4 in PBST containing $1 \%$ bovine serum albumin (BSA). IgE antibodies were detected using biotinylated goat anti-human IgE (Vector, Burlingame, Calif., USA) and streptavidin peroxidase (Sigma-Aldrich, St. Louis, Mo., USA). Color was developed with 3,3',5,5'-tetramethylbenzidine (Kirkegaard and Perry Laboratories, Gaithersburg, Md., USA), and absorbance was measured at $450 \mathrm{~nm}$ after the addition of $0.5 \mathrm{M} \mathrm{H}_{2} \mathrm{SO}_{4}$. The cutoff value was determined as the mean absorbance plus two times the standard deviation of negative controls.

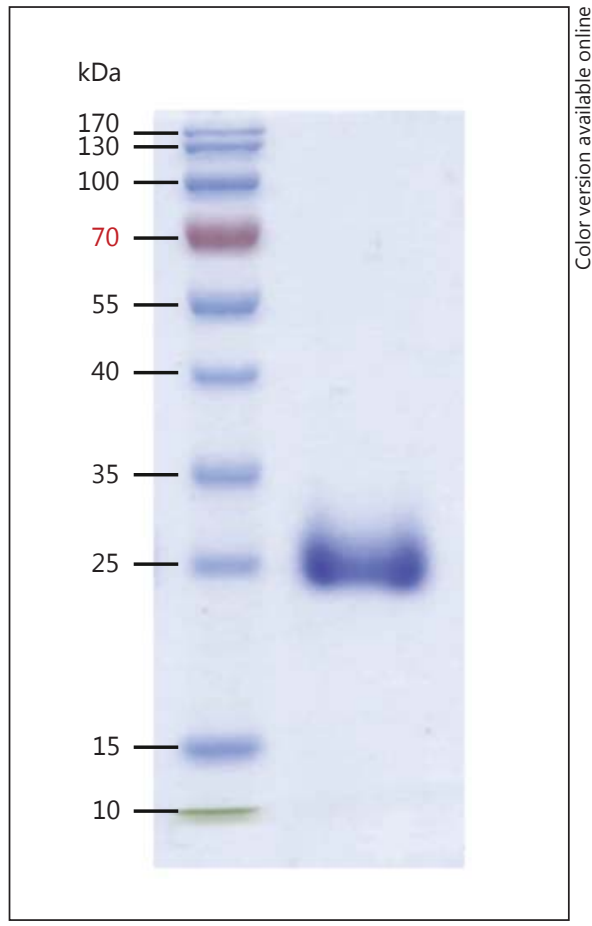

Fig. 1. Purification of the recombinant antigen 5 from the Asian needle ant. The protein $(5 \mu \mathrm{g})$ was separated under reducing conditions on $12 \%$ acrylamide gel and stained with Coomassie brilliant blue.
Fig. 2. IgE reactivity of the recombinant antigen 5 from the Asian needle ant. The dotted line indicates the cutoff value. D. $=$ Dermatophagoides.

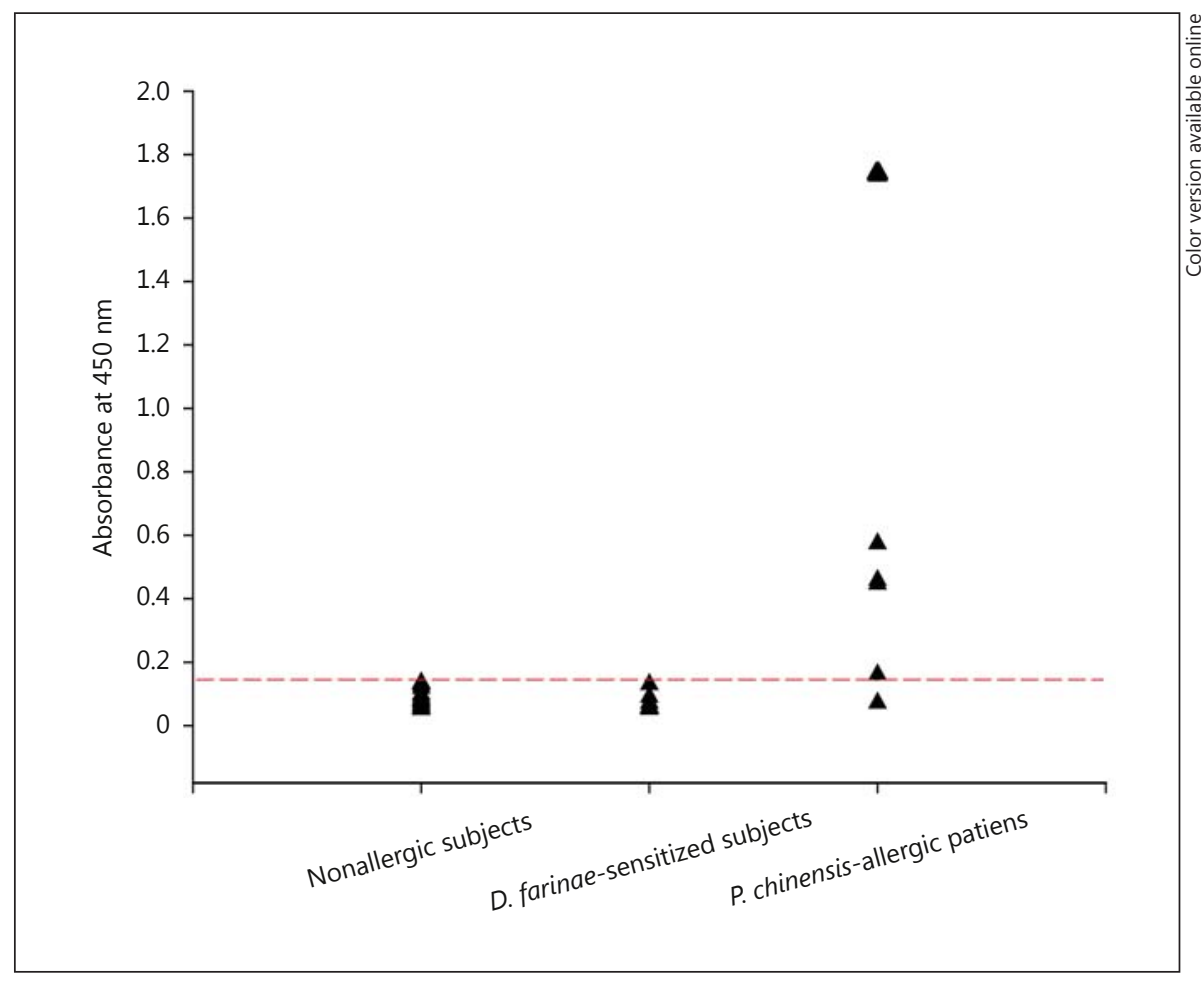

Recombinant Pac c 3 from the Asian Needle Ant
Int Arch Allergy Immunol 2016;169:93-100 DOI: $10.1159 / 000444364$ 
IgE Immunoblotting and IgE Inhibition

Allergen extract from the venom sac, prepared as previously described [8], was separated on $12 \%$ polyacrylamide gels containing SDS under reducing conditions. The separated proteins were electrophoretically transferred onto a polyvinylidene difluoride (PVDF) membrane (GE Waters and Process Technologies, Trevose, Pa., USA). After blocking with $3 \%$ skim milk in PBST, allergens were probed with pooled sera from 5 subjects who were positive for recombinant protein according to ELISA (1:4 diluted in PBST containing 1\% BSA). Allergen-specific IgE antibodies were detected in a 1:1,000 dilution of alkaline phosphatase-conjugated goat anti-human IgE (Sigma-Aldrich) for $1 \mathrm{~h}$, and color was developed with nitro blue tetrazolium and 5-bromo-4-chloro-3-indolyl-phosphate (Promega, Madison, Wis., USA).

For inhibition of IgE responses, the serum sample was incubated with $20 \mu \mathrm{g} / \mathrm{ml}$ of recombinant protein at $4^{\circ} \mathrm{C}$ overnight, and immunoblotting was performed as described above.

Cross-Reactivity with Ves $v 5$

IgE reactivity to recombinant Ves v 5 (i209) and Pac c 3 was measured by ImmunoCAP (Phadia Uppsala, Sweden). For ImmunoCAP analysis, recombinant Pac c 3 was biotinylated using EZLink ${ }^{\circledR}$ Sulfo-NHS-LC-Biotin (Thermo Scientific, Waltham, Mass., USA). Using selected serum samples which showed IgE reactivity to recombinant Ves v $5\left(4.95\right.$ and $\left.7.2 \mathrm{kU}_{\mathrm{A}} / \mathrm{ml}\right)$, inhibition analysis was performed in order to evaluate the cross-reactivity between Ves $v 5$ and Pac c 3 . The serum sample was incubated with various concentrations of recombinant Pac c 3 (5-fold serially diluted from $30 \mu \mathrm{g} / \mathrm{ml}$ ), and IgE reactivity to recombinant Ves $\mathrm{v} 5$ was measured by ImmunoCAP. The inhibition percentage of IgE binding to Ves v 5 by recombinant Pac c 3 was calculated as $\left(1-A_{i} / A_{0}\right) \times 100$, where $A_{i}$ stands for the IgE value with an inhibitor, and $A_{0}$ for the IgE value without an inhibitor.

\section{Circular Dichroism}

The far UV circular dichroism (CD) spectrum of recombinant Pac c 3 was recorded at concentrations of $0.15 \mathrm{mg} / \mathrm{ml}$ in $50 \mathrm{mM}$ sodium phosphate, $150 \mathrm{mM} \mathrm{NaCl}, \mathrm{pH}$ 7.6, between 185 and 265 $\mathrm{nm}$, using a J-810 spectropolarimeter (Jasco, Gross-Umstadt, Germany) with temperature controlled at $20^{\circ} \mathrm{C}$.

\section{Results}

\section{Production of Recombinant Allergen}

The expression level of recombinant Pac $\mathrm{c} 3$ in the culture media was measured every $24 \mathrm{~h}$ for 4 days. Secretion of recombinant protein was detected only after $24 \mathrm{~h}$ of expression. Recombinant protein was precipitated with 50-70\% ammonium sulfate. Proteins concentrated with $70 \%$ ammonium sulfate were purified by Ni affinity chromatography. Recombinant protein with six histidine residues at the $\mathrm{C}$-terminus and four additional amino acids (GluAlaGluAla) derived from vector sequence (calculated molecular mass is $23.8 \mathrm{kDa}$ ) showed an apparent band of about $24 \mathrm{kDa}$ by SDS-PAGE analysis (fig. 1). The pro- tein yield was $2.78 \mathrm{mg} / \mathrm{l}$ of yeast culture. The Mascot score of the recombinant protein analyzed by LC-coupled ESIMS/MS was 253 with Pac c 3 (gi|313471714).

\section{IgE Reactivity of Recombinant Protein}

Five of $6(83.3 \%)$ serum samples showed positive responses to the recombinant protein (fig. 2). In IgE inhibition blotting analysis, IgE antibody responses to the 23$\mathrm{kDa}$ allergen were almost completely inhibited by preincubation with the recombinant protein (fig. 3).

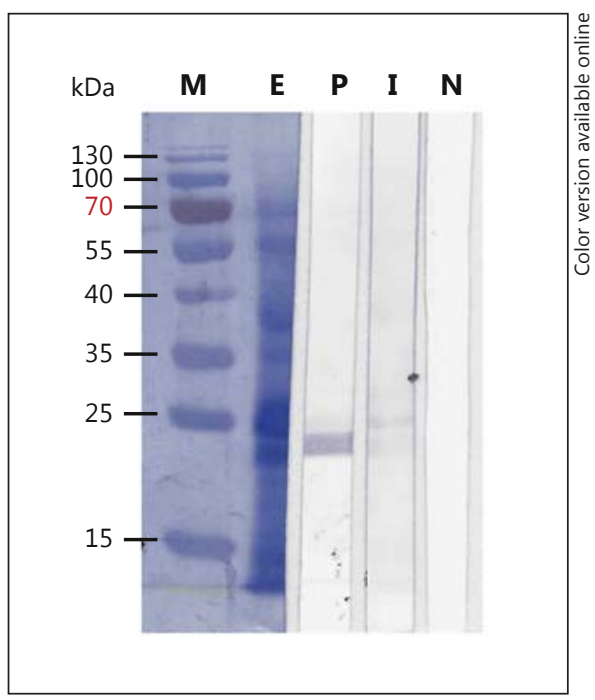

Fig. 3. IgE immunoblot analysis. Asian needle ant venom sac extract was separated by $12 \%$ SDS-PAGE and transferred onto a PVDF membrane. $\mathrm{M}=$ Molecular mass standard; $\mathrm{E}=$ venom sac extract stained with Coomassie blue; $\mathrm{P}=$ IgE-reactive proteins probed with sera from patients without inhibitor; I = IgE-reactive components probed with sera from patients preincubated with inhibitor; $\mathrm{N}=$ buffer control.

Fig. 4. Amino acid sequence alignment of $P$. chinensis antigen 5 allergen with other homologous allergens from Hymenoptera. Pac c $3=P$. chinensis (accession No. EU516327); Sol i $3=$ Solenopsis invicta (AAB36116); Sol r $3=$ S. richteri (P35779); Ves s $5=$ Vespula squamosa (P35786), Ves m $5=V$. maculifrons (ABC73068); Ves v $5=V$. vulgaris (Q05110); Ves f $5=V$. flavopilosa (P35783); Ves g $5=V$. germanica (CAJ28930); Ves p $5=V$. pensylvanica (P35785); Ves vi $5=$ V. vidua (P35787); Dol m $5=$ Dolichovespula maculata (AAA28302); Dol a $5=D$. arenaria (Q05108); Pol d $5=$ Polistes dominula (AAT95010); Pol g $5=$ P. gallicus (P83377); Pol e $5=P$. exclamans (AAT95009); Pol a $5=P$. annularis (Q05109); Pol f $5=P$. fuscatus (P35780); Pol s $5=$ Polybia scutellaris (AAP57536); Ves c 5 = Vespa crabro (P35781). The marks below the amino acid sequence indicate the degree of conservation. ${ }^{*}=$ Identical among species; : = highly conserved; . = less conserved. The percentage of each sequence identity is shown in brackets.

(For figure see next page.)
96

Int Arch Allergy Immunol 2016;169:93-100 DOI: $10.1159 / 000444364$
Jeong/Yi/Son/Lyu/Lee/Yong/Park 


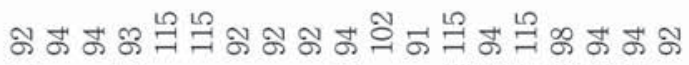

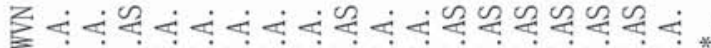

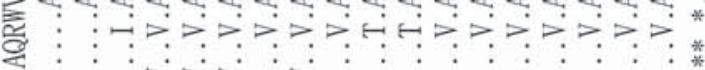

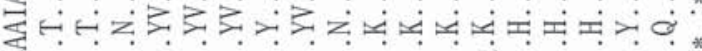

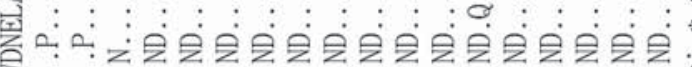

会

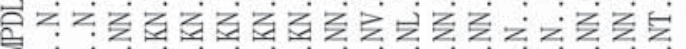

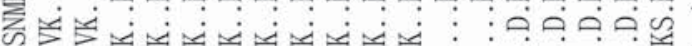

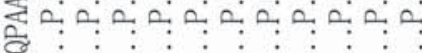

:

光文

密立立

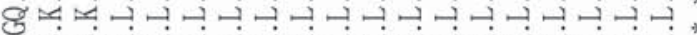

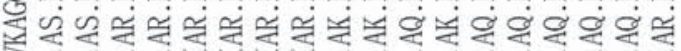
舟我文:

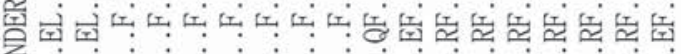

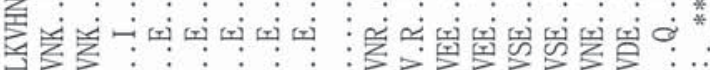

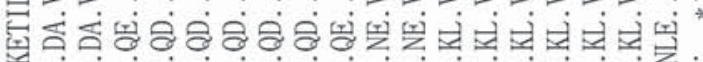

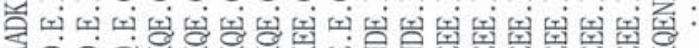

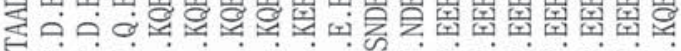

国

i.

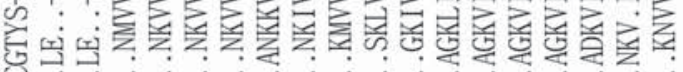

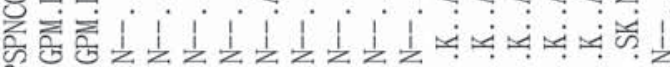

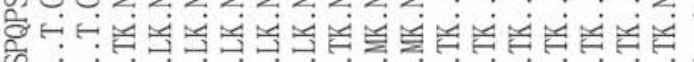

1 : ':

f : : :

吉

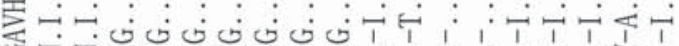

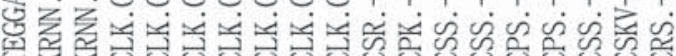

A

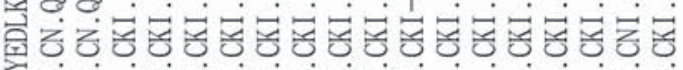

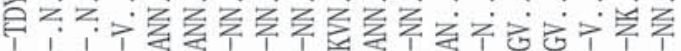

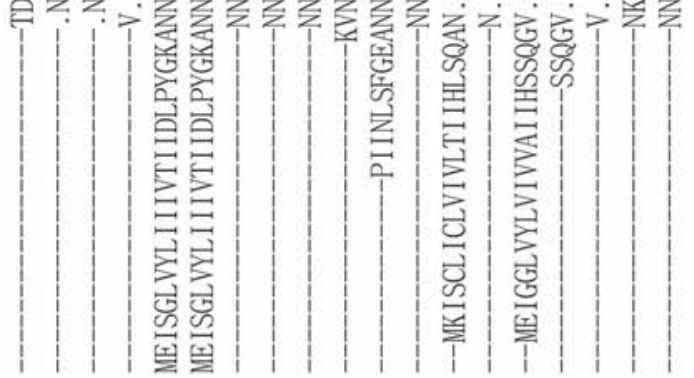

ח U.- 山 ⿰幺𠃌

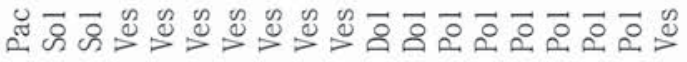

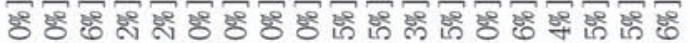

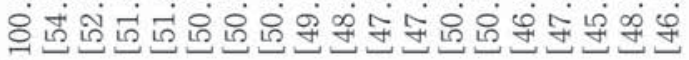

氶

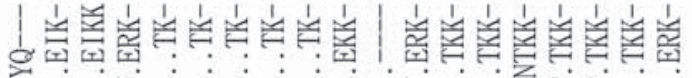

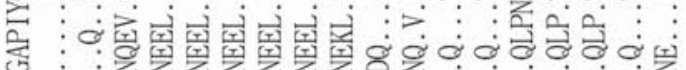

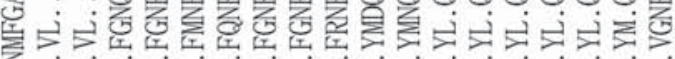

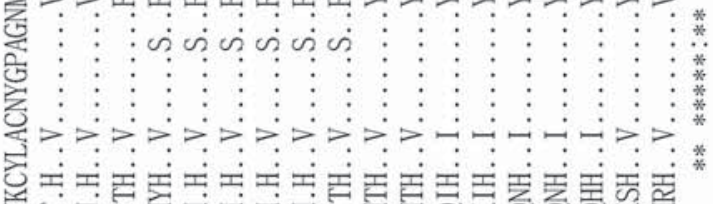

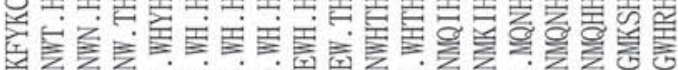

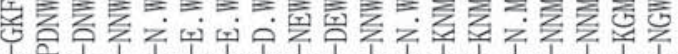

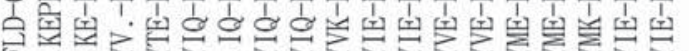

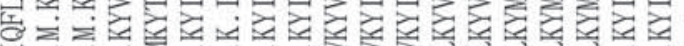

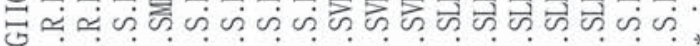

ర్ర్ర

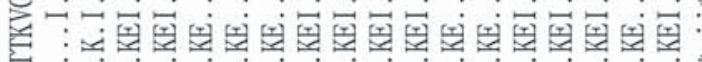

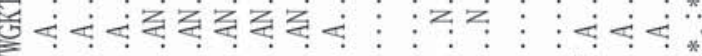

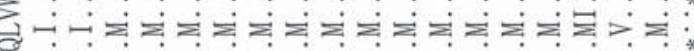

索

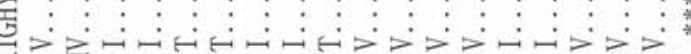

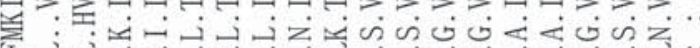

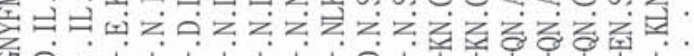

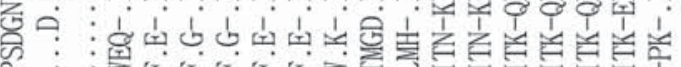

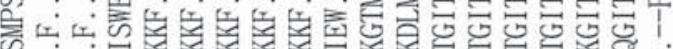
जิ

窟的

年

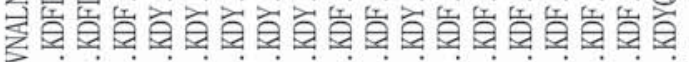

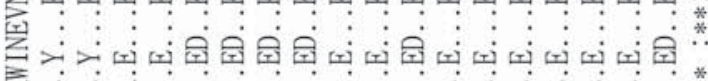

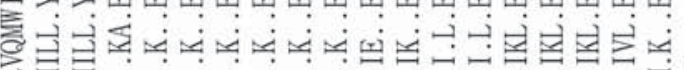
竞言

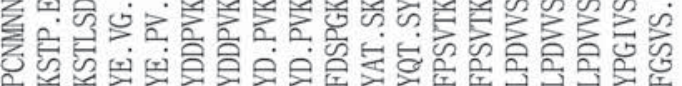

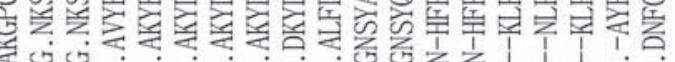

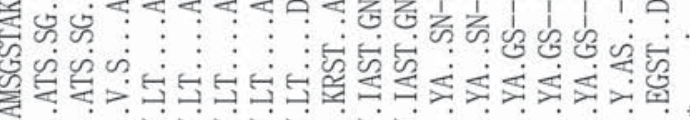
要

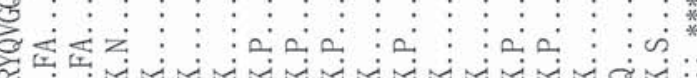

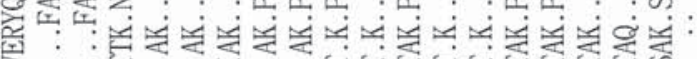

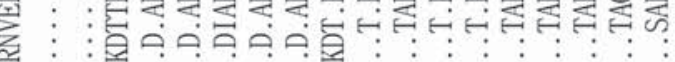

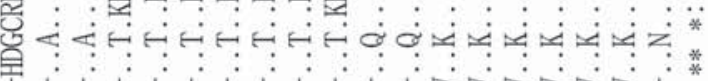

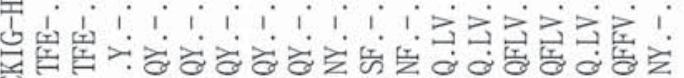

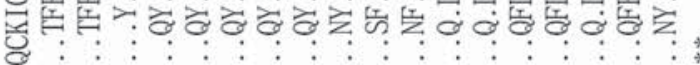

m

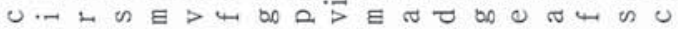

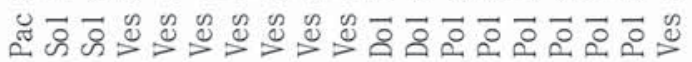


Fig. 5. ImmunoCAP inhibition analysis. Specific IgE to recombinant Ves v 5 was inhibited by recombinant antigen 5 from the Asian needle ant.
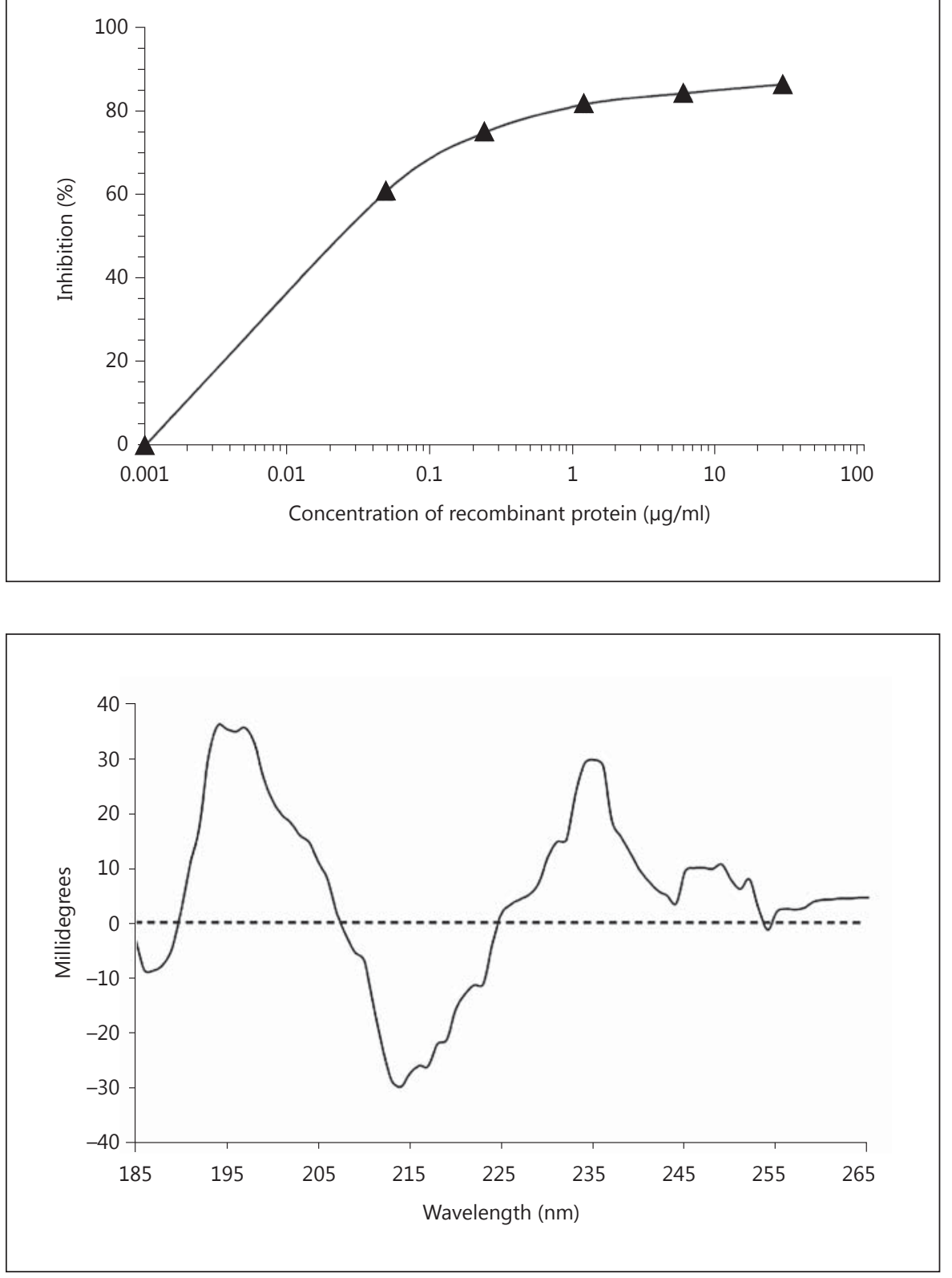

Fig. 6. CD spectrum of recombinant Pacc 3.

Homology and Cross-Reactivity with Vespid Antigen 5 Allergens

A GenBank data search was done and the CLUSTAL $\mathrm{X}$ program was utilized for the sequence alignments with other antigen 5 allergens (fig. 4). Pac c 3 was shown to share the highest identity with Sol i 3, followed by Sol $r 3$. It shares $45.5-51.2 \%$ sequence identity to vespid antigen 5 proteins. There was no potential glycosylation site.

In order to investigate cross-reactivity, IgE reactivity to recombinant Ves v 5 (i209) and Pac c 3 was measured by
ImmunoCAP using serum samples from patients with anaphylaxis to the Asian needle ant. Specific IgE to recombinant Pac c 3 was determined to be $1.30-35.60(0.05,1.30$, $4.12,4.21,17.10$ and 35.60$) \mathrm{kU}_{\mathrm{A}} / 1$ by ImmunoCAP. Five sera which recognized recombinant Pac c 3 showed 0.28$7.20(0.05,0.28,1.80,1.81,4.95$ and 7.20$) \operatorname{IgE~kU}_{\mathrm{A}} / 1$ to recombinant Ves $\mathrm{v} 5$, even though amino acid sequence identity between two molecules is only $50.0 \%$ (fig. 4). IgE reactivity to recombinant Ves $\mathrm{v} 5$ and Pac c 3 showed a strong correlation (0.974; Pearson's correlation coefficient, 
$\mathrm{p}=0.01)$. Recombinant Pac c 3 was able to inhibit $86.4 \%$ IgE binding to Ves v 5 (fig. 5). Dose-dependent inhibition of IgE binding to recombinant $\mathrm{Ves} v 5$ by recombinant $\mathrm{Pac}$ c 3 indicates the cross-reactivity between these molecules.

We analyzed the structural feature of recombinant $\mathrm{Pac}$ c 3 by means of CD spectroscopy (fig. 6). The CD spectrum was recorded (minimum at $214 \mathrm{~nm}$ and maximum at $194 \mathrm{~nm})$.

\section{Discussion}

In this study, we describe the successful production of a recombinant Pac c 3 allergen, homologous to antigen 5 allergens, using a Pichia expression system (fig. 1). Antigen 5 proteins from various hymenopteran insects have been demonstrated to be potent allergens [19].

Expression of recombinant antigen 5 in prokaryotic systems is often frustrating because of incorrect folding or lack of proper posttranslational modification [20]. Dol m 5 (antigen 5 from the hornet Dolichovespula maculata) was successfully expressed using a baculovirus system [21]. The host insect cells showed premature melanization, low weight gain and an enhanced morbidity at the beginning. However, these limitations were overcome with advanced technologies, and insect cell lines have developed to very useful systems for the production of correctly folded venom allergens $[22,23]$. The methylotrophic yeast Pichia pastoris is an alternative for the vespid venom expression. Recombinant Ves $\mathrm{v} 5$ (antigen 5 from the yellow jacket Vespula vulgaris) and Pol a 5 (antigen 5 from the paper wasp Polistes annularis) expressed in yeast Pichia were shown to have conformations similar to those of their native counterparts [24].

Yeast expression was described as advantageous for the expression of antigen 5 because of the ease of purification [24]. However, we observed loss of recombinant protein during long periods of culture ( $>48 \mathrm{~h}$ ), possibly due to degradation by yeast proteases [25]. Native antigen 5 is known to be modified posttranslationally, including hydroxylation, phosphorylation and glycosylation [26]. The effect of these modifications on IgE reactivity should be further investigated. Recently, antigen 5 molecules from the wasp were shown to be useful for distinguishing between allergies to honey bee or vespid venom [15-17, 27, 28].

The recombinant protein produced in this study showed good allergenic activity (fig. 2, 3). Pac c 5 seems to represent by far the most important allergen in the Asian needle ant, since hardly any other IgE-reactive band is detected by IgE immunoblotting after inhibition with re-

Recombinant Pac c 3 from the Asian Needle Ant combinant Pac c 3 (fig. 3). All of the serum samples used in this study were obtained from patients with a history of anaphylaxis. Therefore, the recombinant Pac c 3 allergen might be useful for the diagnosis of allergy to Asian needle ant stings. Interestingly, 5 of 6 serum samples which showed IgE reactivity to recombinant Pac $\mathrm{c} 3$ also showed IgE binding to recombinant Ves $v 5$, even though sequence identity was only $50.0 \%$ (fig. 4 ; table 1 ). Two patients had not only a history of ant sting but also of bee sting allergy (table 1). However, antigen 5 allergen is not present in bee venom. Moreover, $V$. vulgaris, from which Ves $v 5$ is produced, is not native to Korea. Six species of yellow jackets ( $V$. austriaca, $V$. flaviceps flaviceps, V. germanica, $V$. koreensis koreensis, $V$. rufa schrenckii and $V$. shidai) have been described in Korea [29]. Therefore, IgE reactivity to Ves v 5 is a reflection of the cross-reaction, and the Asian needle ant is the obvious primary sensitizer. IgE reactivity to Ves $\mathrm{v} 5$ and Pac $\mathrm{c} 3$ showed a statistically significant correlation $(\mathrm{p}=0.01)$, indicating possible cross-reactivity. Recombinant Pac c 3 was able to inhibit IgE binding to Ves $v 5$ by ImmunoCAP inhibition, indicating the cross-reactivity between these allergens (fig. 5). Conformational epitopes are thought to be important for the IgE recognition of antigen 5 allergens. Overall folding of the recombinant Pac c 3 is different from other antigen 5 allergens, as indicated by $\mathrm{CD}$ analysis (fig. 6). A similar pattern of the CD spectrum was observed between 185 and $201 \mathrm{~nm}$. However, a peak around $235 \mathrm{~nm}$ makes it different from the other antigen 5 allergens. High contents of Tyr and Trp are known to peak between 225 and $235 \mathrm{~nm}$, but Pac c 3 contains only 10 Tyr and 4 Trp in the sequences. Other possibilities are collagen-like triple helices which produce a positive $\mathrm{CD}$ peak in the region of 231-235 nm [30]. Possibly, partially degraded fragments may form triple helical structures. Nevertheless, it is believed to retain the conformation of IgE epitope regions of a native counterpart as a strong $\operatorname{IgE}$ reactivity and cross-reactivity with Ves $\mathrm{v} 5$ was observed. Further studies are needed to investigate the clinical relevance of the cross-reactivity among ant, wasp, yellow jacket and hornet. Application of this recombinant allergen to treatment may also be feasible, and further studies are needed to investigate this concept.

In conclusion, we produced a recombinant Pac c 3 with good allergenic potential. The recombinant protein was recognized by IgE antibodies from $83.3 \%$ of the patients who had experienced an anaphylactic episode to an ant sting. Although further characterization of this ant allergen is needed, this recombinant protein will be useful for clinical allergy applications such as diagnosis and treatment. 


\section{Acknowledgments}

\section{References}

1 Kang SY, Chang SI, Min KU, Moon HB, Kim YY: A case of systemic reaction induced by ant venom allergy. J Korean Soc Allergol 1985;5:183-189.

2 Kim SC, Hong CS: A case of anaphylaxis by ant (Ectomomyrmex spp.) venom and measurement of specific IgE and IgG subclasses. Yonsei Med J 1992;33:281-287.

3 Kang JD, Kim SJ, Youn NH, Kim BJ, Park SD: A case of ant sting by Crematogaster matsumurai vagala. Ann Dermatol 2004;16:87-89.

4 Kim BJ, Kim JH, Kim KG: Systemic study of Ponerinae (Hymenoptera: Formicidae) from Korea. Korean J Entomol 1998;28:145-154.

5 Yun YY, KoSH, Park JW, Hong CS: Anaphylaxis to venom of the Pachycondyla species ant. J Allergy Clin Immunol 1999;104:879882.

6 Kim SS, Park HS, Kim HY, Lee SK, Nahm DH: Anaphylaxis caused by the new ant, Pachycondyla chinensis: demonstration of specific IgE and IgE-binding components. J Allergy Clin Immunol 2001;107:1095-1099.

7 Cho YS, Lee YM, Lee CK, Yoo B, Park HS, Moon HB: Prevalence of Pachycondyla chinensis venom allergy in an ant-infested area in Korea. J Allergy Clin Immunol 2002;110:5457.

8 Lee EK, Jeong KY, Lyu DP, Lee YW, Sohn JH, Lim KJ, Hong CS, Park JW: Characterization of the major allergens of Pachycondyla chinensis in ant sting anaphylaxis patients. Clin Exp Allergy 2009;39:602-607.

9 King TP, Valentine MD: Allergens of hymenopteran venoms. Clin Rev Allergy 1987; 5:137-148.

10 Abe T, Kawai N, Niwo A: Purification and properties of a presynaptically acting neurotoxin, mandaratoxin, from hornet (Vespa mandarinia). Biochemistry 1982;21:16931697.

11 Henriksen A, King TP, Mirza O, Monsalve RI Meno K, Ipsen H, Larsen JN, Gajhede M, Spangfort MD: Major venom allergen of yellow jackets, Ves v 5: structural characteriza-
This research was supported by a grant from the Korea Healthcare Technology R\&D Project through the Korean Health Industry Development Institute funded by the Ministry of Health, Welfare and Family Affairs, Republic of Korea (HI14C1324). tion of a pathogenesis-related protein superfamily. Proteins 2001;45:438-448.

12 Ribeiro JM, Francischetti IM: Role of arthropod saliva in blood feeding: sialome and postsialome perspectives. Annu Rev Entomol 2003;48:73-88.

13 Zeleznick LD, Hunt KJ, Sobotka AK, Valentine MD, Tippett LO, Lichtenstein LM: Diagnosis of Hymenoptera hypersensitivity by skin testing with Hymenoptera venoms. J Allergy Clin Immunol 1977;59:2-9.

14 Hunt KJ, Valentine MD, Sobotka AK, Benton AW, Amodio FJ, Lichtenstein LM: A controlled trial of immunotherapy in insect hypersensitivity. N Engl J Med 1978;299:157161.

15 Jin C, Focke M, Leonard R, Jarisch R, Altmann F, Hemmer W: Reassessing the role of hyaluronidase in yellow jacket venom allergy. J Allergy Clin Immunol 2010;125:184-190.

16 Sturm GJ, Jin C, Kranzelbinder B, Hemmer W, Sturm EM, Griesbacher A, Heinemann A, Vollmann J, Altmann F, Crailsheim K, Focke $\mathrm{M}$, Aberer W: Inconsistent results of diagnostic tools hamper the differentiation between bee and vespid venom allergy. PLoS One 2011;6:e30842.

17 Monsalve RI, Vega A, Marques L, Miranda A, Fernandez J, Soriano V, Cruz S, DominquezNoche C, Sanchez-Morillas L, Armisen-Gil M, Guspi R, Barber D: Component-resolved diagnosis of vespid venom-allergic individuals: phospholipases and antigen $5 \mathrm{~s}$ are necessary to identify Vespula or Polistes sensitization. Allergy 2012;67:528-536.

18 Muller U, Schmid-Grendelmeier P, Hausmann $\mathrm{O}$, Helbling A: IgE to recombinant allergens Api m 1, Ves v 1, and Ves v 5 distinguish double sensitization from crossreaction in venom allergy. Allergy 2012;67:1069-1073.

19 Hoffman D: Hymenoptera venom allergens. Clin Rev Allergy Immunol 2006;30:109-128.

20 Jeong KY, Hong CS, Yong TS: Recombinant allergens for diagnosis and immunotherapy of allergic disorders, with emphasis on cock- roach allergy. Curr Protein Pept Sci 2006;7: 57-71.

21 Tomalski MD, King TP, Miller LK: Expression of hornet genes encoding venom allergen antigen 5 in insects. Arch Insect Biochem Physiol 1993;22:303-313.

22 Schmidt M, McConnell TJ, Hoffman DR: Immunologic characterization of the recombinant fire ant venom allergen Sol i 3. Allergy 2003;58:342-349.

23 Ollert M, Blank S: Anaphylaxis to insect venom allergens: role of molecular diagnosis. Curr Allergy Asthma Rep 2015;15:26.

24 Monsalve RI, Lu G, King TP: Expressions of recombinant venom allergen, antigen 5 of yellowjacket (Vespula vulgaris) and paper wasp (Polistes annularis), in bacteria or yeast. Protein Expr Purif 1999;16:410-416.

25 Macauley-Patrick S, Fazenda ML, McNeil B, Harvey LM: Heterologous protein production using the Pichia pastoris expression system. Yeast 2005;22:249-270.

26 Dos Santos-Pinto JR, Dos Santos LD, Andrade Archuri H, Castro FM, Kalil JE, Palma MS: Using proteomic strategies for sequencing and post-translational modifications assignment of antigen-5, a major allergen from the venom of the social wasp Polybia paulista. J Proteome Res 2014; 13:855-865.

27 De Graaf DC, Aerts M, Danneels E, Devreese B: Bee, wasp and ant venomics pave the way for a component-resolved diagnosis of sting allergy. J Proteomics 2009;72:145-154.

28 Pesek RD, Lockey RF: Management of insect sting hypersensitivity: an update. Allergy Asthma Immunol Res 2013;5:129-137.

29 Choi MB, Kim JK, Lee JW: Checklist and distribution of Korean Vespidae revisited. Korean J Appl Entomol 2013;52:85-91.

30 Wetzel R, Buder E, Hermel H, Hutter A: Conformations of different gelatins in dilutions and in films: an analysis of circular dichroism (CD) measurements. Colloid Polym Sci 1987; 265:1036-1045. 